\title{
Análisis comparativo de seis lugares de interés para la ubicación de instrumentación astronómica en Colombia
}

\author{
Giovanni Pinzón 1,*, Danilo González', Aura Ramírez ${ }^{2}$ \\ ${ }^{1}$ Observatorio Astronómico, Facultad de Ciencias, Universidad Nacional de Colombia, Bogotá, Colombia \\ ${ }^{2}$ Departamento de Física, Universidad Nacional de Colombia, Bogotá, Colombia
}

\begin{abstract}
Resumen
En este trabajo se presentan los resultados de una campaña observacional de tres años durante la cual se realizaron medidas de la calidad del cielo in-situ en seis sitios de interés astronómico en los departamentos de Santander, Boyacá, Tolima, Huila, Cesár y La Guajira. Se realizaron excursiones esporádicas y de corta duración a estos seis lugares con el fin de realizar mediciones de temperatura y humedad a lo largo de la noche, del nivel de turbulencia en la vecindad del telescopio ó Seeing, del brillo del cielo y de la extinción atmosférica. La metodología utilizada en las medidas del Seeing se validó a través del uso de imágenes satelitales simultáneas a nuestras visitas, obtenidas de la base de datos del satelite geoestacionario GOES 13. El Seeing es altamente variable a lo largo de la noche en todos los sitios, con valores entre 1" y 4". Las difíciles condiciones climatológicas en especial la elevada humedad registrada durante la campaña, impidieron obtener una estadística mínima de datos fotométricos por lo que el análisis comparativo de los lugares visitados está basado en las medidas de Seeing. Una prueba de Kolmogorov-Smirnov confirma que los valores más bajos se registraron en los lugares de mayor altura en el Oriente colombiano, en particular en el sitio La Bricha, una vereda del municipio de Macaravita en Santander en donde la variabilidad registrada fué la menor con un $r m s=0,59^{\prime \prime}$. Este hecho sumado a la humedad inferior a $85 \%$ incluso durante la madrugada y el bajo nivel observado en el brillo de cielo sugieren que de los lugares visitados durante la campaña, La Bricha puede considerarse como un sitio apropiado para la ubicación de instrumentación astronómica en el rango óptico. No obstante, se recomienda realizar un monitoreo a largo plazo con el fin de caracterizar completamente el lugar.
\end{abstract}

Palabras clave: turbulencia atmosférica, búsqueda de sitio en Colombia, GOES 13.

Comparative analysis of six interesting sites for astronomical instrumentation in Colombia

\begin{abstract}
In this work we present the results obtained from an observational campaign aimed to conduct measurements in-situ of the quality of the sky at six sites with astronomical interest in Santander, Boyacá, Tolima, Huila, Cesár and La Guajira. Short and sporadic expeditions were done to those places with the main goal to conduct measurements of temperature, humidity during the night, the level of turbulence in the vicinity of the telescope, the Seeing, the sky brightness and the atmospheric extinction. The adopted methodology for the Seeing measurements was validated with satellite data simultaneous to our visits, obtained from the data archive of the geostationary satellite GOES 13. All sites present Seeing highly variable along the night with values between 1" and 4". The bad weather and specially, the high humidity registered during the campaign limited the quality of photometric data and subsequently, the comparative analysis of the visited sites is based on the Seeing measurements. An statistical KolmogorovSmirnov test confirm that the lowest values are observed in high altitude sites over the Eastern Andes in particular at La Bricha in Macaravita-Santander where we get the lowest variability with $r m s=0,59^{\prime \prime}$. This fact together with the low humidity, less than $85 \%$ even during the dawn and the low level of the sky brightness suggest that La Bricha is a suitable place for location of astronomical instrumentation in the visible range. However, it is highly recommended to conduct a long-term monitoring of the place with the aim to characterize the site properly.
\end{abstract}

Key words: Atmospheric turbulence, site testing in Colombia, GOES 13.

\section{Introducción}

La turbulencia en la atmósfera es una característica importante a tener en cuenta en el proceso de selección de lugares para la ubicación de instrumentación astronómica sobre todo en la región del óptico y del infrarrojo. En condiciones de cielo despejado, la turbulencia limita la resolución de los telescopios y restringe el valor del umbral de detección y el intervalo de longitud de onda dentro del cual las observaciones son posibles. Si bien otros factores como bajos niveles de extinción atmosférica y de brillo del cielo son característicos de un buen lugar de observación, un bajo nivel de turbulencia atmosférica es fundamental para obtener imágenes y espectros ópticos de buena calidad. La 
identificación de lugares dentro de una región de interés en donde el efecto de la turbulencia es mínimo, se realiza a través de medidas in-situ del nivel de degradación de la imagen de objetos puntuales a lo largo de la noche. Dicha metodología se aplicó en la selección del sitio para la ubicación del VLT (Very Large Telescope), del complejo astronómico de La Silla, ambos en el norte de Chile (Stock, 1964), del observatorio de Roque de los Muchachos en las Islas Canarias (Cavazzani, et al., 2011; Della Valle, et al., 2010) y en un estudio sobre búsqueda de sitio en Indonesia (Hidayat, et al., 2012).

La identificación de posibles lugares para la ubicación de un telescopio óptico nacional con instrumentación encaminada a fortalecer actividades de investigación, formación y extensión en Universidades y Colegios principalmente, es una tarea compleja toda vez que Colombia se encuentra dentro de la Zona de Confluencia Intertropical (ZCIT) la cual se caracteriza por tener alta nubosidad. El clima en Colombia está gobernado por un ciclo bimodal anual con dos épocas secas y dos de lluvia durante el año (Poveda, 2011). No obstante, se espera que en la región visible del espectro electromagnético, existan algunos lugares con cielos claros durante las temporadas secas con características como calidad del cielo aceptable, horizonte despejado, ausencia de tormentas y velocidad del viento inferior a $20 \mathrm{~km} / \mathrm{h}$. Estos lugares aún no se han identificado ni monitoreado toda vez que los estudios previos sobre búsqueda de sitio en Colombia son muy escasos. Brieva (1985) realizó una campaña observacional con el fin de cuantificar el porcentaje de cielo cubierto durante la noche en cuatro lugares sobre las cordilleras Andinas. En su trabajo basado en datos de inspección visual del cielo se reportan entre 130 y 250 noches utilizables por año en El Otún $\left(4^{\circ} 45^{\prime}, 72^{\circ} 25^{\prime}\right)$, un sitio a 4000 de altura sobre la cordillera central.

En un trabajo reciente, Pinzón, et al. (2015) identificaron doce lugares potenciales en la región que comprende Colombia, el Oeste de Venezuela y el Norte de Ecuador, ocho de ellos en el territorio Colombiano. La metodología implementada en dicho estudio se basa en un algoritmo que predice el porcentaje de cielo claro en un lugar determinado. Este porcentaje se calcula tres veces durante cada una de las noches de los años 2008 a 2012 a través de la comparación entre la temperatura de brillo obtenida del análisis conjunto de imágenes satelitales de Colombia en el infrarrojo y registros históricos de temperatura proporcionados por estaciones meteorológicas en tierra. Adicionalmente se utilizan datos de temperatura de la alta tropósfera obtenidos de bases de datos de radio sondeos. La validación del algoritmo se realizó con registros diarios de cubrimiento del

\footnotetext{
*Correspondencia:

Giovanni Pinzón, gapinzone@unal.edu.co

Recibido: 12 de octubre de 2015

Aceptado: 15 de febrero de 2016
}

cielo durante las noches de los mismos años, obtenidos en los reportes del Observatorio Nacional de Llano del Hato en Venezuela. La diferencia porcentual anual máxima entre los valores reportados y predichos por el algoritmo es inferior al $20 \%$.

El mapa de número de noches despejadas por año (en adelante NDA) correspondiente al análisis de cinco años de imágenes en dos bandas infrarrojas del satélite GOES se encuentra en la Figura 1. Los mejores lugares se encuentran en Venezuela, principalmente en la región sobre los Andes, comprendida entre las ciudades de Timotes y Trujillo con 208 NDA. En Colombia, la región con mayor número de noches claras se localiza en la parte nororiental de la Sierra Nevada de Santa Marta con (126 \pm 34$)$ NDA, seguida de una zona amplia en la Serranía del Perijá, al oriente de Codazzi, cerca a la frontera con Venezuela con $(111 \pm 27)$ NDA. Lugares con número similar de noches claras se encuentran en los alrededores de Chitagá en Norte de Santander con (107 \pm 23) NDA mientras que en el cañón del río Nevado, entre Macaravita y el Cocuy, en el norte de Boyacá se encuentran lugares con entre 90 y 100 NDA. La mayoría de regiones restantes sobre los Andes presentan valores inferiores a 60 NDA mientras que en lugares de baja altitud se obtienen del orden de 40 NDA (González, 2014).

En este trabajo se presentan los resultados de la campaña observacional asociada a los lugares identificados en el estudio mencionado. Durante tres años se realizaron excursiones esporádicas y de duración corta a cuatro de dichos sitios y a dos lugares con altitud inferior a 450

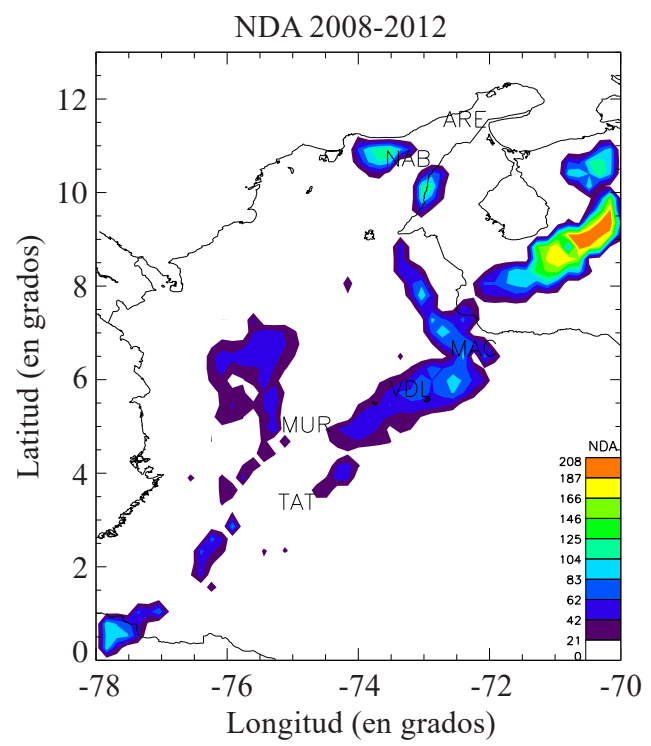

Figura 1. Mapa del número de noches despejadas por año (NDA) en Colombia para los años 2008-2012. Se indican los sitios analizados en este trabajo de la siguiente manera: $\mathrm{ARE}=$ Aremasain (La Guajira), NAB=Nabusimake (Cesár), MAC $=$ Macaravita (Santander), VDL= Villa de Leyva (Boyacá), MUR= Murillo (Tolima) y TAT $=$ Tatacoa (Huila). 
metros sobre el nivel del mar, con el fin de medir la calidad del cielo in-situ. En particular, se efectuaron medidas de Seeing, del coeficiente de extinción atmosférico, de temperatura, de humedad relativa y del brillo del cielo a lo largo de la noche. Con base en estos registros y en un proceso cuidadoso de validación de las medidas de turbulencia atmosférica, se realizó un análisis comparativo tendiente a identificar el mejor lugar.

El proceso de adquisición y análisis de los datos obtenidos durante las visitas a los lugares de interés, en particular, las mediciones de Seeing y de coeficiente de extinción atmosférico se describen en la sección Metodología y Resultados.

\section{Metodología y Resultados}

\section{Observaciones}

Las medidas de calidad de cielo se obtuvieron durante visitas de corta duración a los sitios más cercanos a los reportados por Pinzón, et al. (2015). Se visitaron cuatro lugares situados en altitudes superiores a 2000 metros, localizados dentro de un radio de 20 kilómetros con centro en las coordenadas reportadas en dicho estudio y dos lugares de referencia en altitudes de 7 y 450 metros. La aproximación a lugares más cercanos a los reportados en el estudio previo, presentó dificultades relacionadas con falta de vías de acceso, seguridad y condiciones mínimas de trabajo durante la noche. La Tabla 1 contiene información sobre las coordenadas geográficas de cada lugar, el identificador (ID), la altura sobre el nivel del mar y en la última columna información sobre las fechas de la visita realizada a cada sitio.

El principal objetivo fue realizar en cada sitio medidas de Seeing utilizando un monitor diferencial de imagen ó DIMM, medidas del coeficiente de extinción atmosférica, del brillo del cielo y de las variables meteorológicas temperatura del aire y humedad relativa utilizando el siguiente equipo básico: 1) Estación meteorológica portátil, 2) DIMM
(Telescopio Celestron Nexstar-8 con una cámara de video DSLR), 3) Telescopio Celestron CGE-PRO $11(27,94 \mathrm{~cm})$ con una cámara CCD modelo SBIG ST-402ME con rueda de filtros fotométricos ópticos tipo Bessel $B V I$, destinado a medidas de extinción atmosférica y 4) Medidor de brillo del cielo (SQM por sus siglas en inglés). Adicional-mente, se descargaron 20 imágenes por noche en tres filtros, para cada lugar y en las fechas de nuestra visita de la base de datos del satélite GOES13, con el fin de realizar la validación de los datos obtenidos con el DIMM.

La rutina en cada lugar consistió en monitorear la temperatura y la humedad relativa a lo largo de cada una de las noches de la visita, monitorear el nivel de turbulencia obteniendo videos de corta duración $(\sim 15 s)$ con cadencia de media hora usando el DIMM y cuando la humedad lo permitía y el cielo estaba despejado, obtener imágenes CCD en tres filtros fotométricos de estrellas estándar antes y después del tránsito. El brillo del cielo se midió una vez por noche al comienzo o al final dependiendo de la presencia o no de la Luna, usando el SQM en los ocho valores de acimut siguientes: 0, 45, 90, 135, 180, 225, 270 y 315 grados. Para cada valor de acimut se obtuvieron tres medidas en 0, 45 y 90 grados de altura.

La nubosidad y la elevada humedad presente durante toda la campaña restringieron tanto el número como la calidad de las imágenes astronómicas. Con excepción del sitio Aremasain en La Guajira, la observación se redujo a las estrellas estándar de tipo A0 más brillantes en el firmamento. La baja humedad de Aremasain permitió un registro de 35 imágenes CCD en los tres filtros para todas las noches de la visita en contraste con Nabusimake y La Bricha en donde se lograron respectivamente 6 y 7 imágenes por noche, en los tres filtros. En los otros tres lugares la condensación de agua en los equipos hizo imposible la obtención de datos fotométricos de calidad aceptable.

Tabla 1. Lugares visitados durante la campaña observacional 2013-15. El identificador de cada sitio (ID) en la primera columna corresponde a la localidad más próxima a las coordenadas indicadas en las columnas 3 y 4 . La altura de cada sitio se indica en la columna 5 y la columna 6 contiene información sobre parámetros usados en el proceso de validación de las medidas realizadas con el DIMM.

\begin{tabular}{|c|c|c|c|c|c|c|}
\hline ID & Sitio & Lat.(N) & Lon.(O) & $z(m)$ & $\Lambda(z)$ & Noches \\
\hline \multirow{2}{*}{ MAC } & Alto de los Rayos & 6³0’7”' & $72^{\circ} 36^{\prime} 32^{\prime \prime}$ & 3000 & $\ldots$ & 5-8 enero 2014 \\
\hline & La Bricha & $6^{\circ} 30^{\prime} 47^{\prime \prime}$ & $72^{\circ} 33^{\prime} 22^{\prime \prime}$ & 2600 & $2 \times 10^{-8}$ & 9-11 enero 2014 \\
\hline ARE & Aremasain & $11^{\circ} 29^{\prime} 53^{\prime \prime}$ & $72^{\circ} 41^{\prime} 49^{\prime \prime}$ & 7 & $1 \times 10^{-11}$ & 29 julio - 5 agosto 2013 \\
\hline \multirow{3}{*}{ VDL } & El Infiernito & $5^{\circ} 38^{\prime} 44^{\prime \prime}$ & 73³3’32” & 2100 & $\ldots$ & 9-11 agosto 2013 \\
\hline & Museo Paleontológico & $5^{\circ} 38^{\prime} 37^{\prime \prime}$ & $73^{\circ} 30^{\prime} 58^{\prime \prime}$ & 2200 & $5 \times 10^{-9}$ & 6-8 agosto 2013 \\
\hline & & & & & & $18-22$ febrero 2015 \\
\hline \multirow{3}{*}{ TAT } & & & & & & 12-16 marzo 2013 \\
\hline & La Tatacoa & $3^{\circ} 14^{\prime} 4^{\prime \prime}$ & $75^{\circ} 10^{\prime} 12^{\prime \prime}$ & 450 & $1 \times 10^{-11}$ & 18-21 febrero 2014 \\
\hline & & & & & & 1-3 noviembre 2014 \\
\hline MUR & Murillo & $4^{\circ} 54^{\prime} 19^{\prime \prime}$ & $75^{\circ} 13^{\prime} 33^{\prime \prime}$ & 3500 & $\ldots$ & 15-17 febrero 2014 \\
\hline NAB & Nabusimake & $10^{\circ} 34^{\prime} 9 \prime$ & $73^{\circ} 36^{\prime} 2^{\prime \prime}$ & 2000 & $\ldots$ & 20-26 julio 2013 \\
\hline
\end{tabular}


La campaña observacional consistió en excursiones esporádicas y de corta duración a cada lugar por lo que el hecho de obtener pocas imágenes por noche en todos ellos excepto en Aremasain, no es razón suficiente para concluir que el cielo sobre las cordilleras andinas es inapropiado para la astronomía en el óptico. La poca información fotométrica obtenida es una consecuencia de la enorme variabilidad meteorológica presente sobre las cordilleras andinas y en particular de la elevada humedad registrada en lugares a gran altura en comparación con el sitio Aremasain. En las Figuras 4, 5 y 6 se observa que Aremasain es el único sitio en donde se registran valores menores a $85 \%$ de humedad durante la campaña.

\section{Determinación del Seeing atmosférico}

Debido a la turbulencia de la atmósfera, el tamaño de los objetos puntuales se incrementa en comparación con aquel predicho por la teoría de la difracción. Antes de llegar al telescopio, la luz proveniente de una fuente puntual atraviesa distintas capas atmosféricas las cuales perturban su propagación. La imagen que se obtiene, se degrada y su tamaño aumenta de acuerdo con el grado de turbulencia en el entorno del telescopio. El Seeing se define como el diámetro expresado en segundos de arco, de la región circular que contiene la imagen de la fuente puntual degradada por la turbulencia atmosférica. Efectos como variación del brillo en escalas de tiempo del orden de los mili-segundos, aumento en el diámetro angular de las imágenes puntuales y movimiento de estas en el plano focal son consecuencias típicas de un lugar con alto Seeing. Valores menores a un segundo de arco son representativos de sitios a gran altura en el norte de Chile, Sur África, Hawái y las Islas Canarias en España.

La fuente del Seeing es la variación del índice de refracción en las capas atmosféricas. La descripción de la naturaleza de las perturbaciones del frente de onda inducidas por la atmósfera fue descrita por Kolmogorov y Tatarski (1971). La hipótesis principal consiste en considerar la interacción entre una onda plana y monocromática con una delgada capa de la tropósfera (altura inferior a $\sim 12 \mathrm{~km}$ ), como un proceso estocástico y estacionario. Se asume que la capa es un medio inhomogéneo y variable, con índice de refracción aleatorio y en régimen turbulento toda vez que el número de Reynolds cerca a la superficie es mucho mayor que uno. Este número es igual a $R e=V L / v$ en donde $V$ es el flujo de velocidades de las capas atmosféricas, el cual es del orden de $\sim 0,3 \mathrm{~km} / \mathrm{s}$, $v$ es la viscosidad cinemática la cual varía entre $0,132 \mathrm{~cm}^{2} / \mathrm{s}$ a $T=0^{\circ} \mathrm{C}$ y $0,104 \mathrm{~cm}^{2} / \mathrm{s}$ a $T=-40^{\circ} \mathrm{C}$ y $L$ es la longitud característica de las celda turbulenta cercana a la superficie, la cual es del orden de $L \sim 15 \mathrm{~cm}$ (Roddier, 1981).

Consideremos una onda plana monocromática $\psi_{0}(\vec{r})$, que incide sobre una capa atmosférica con espesor $d z$ como se indica en la Figura 2. El frente de onda una vez se cruza dicha capa es $\psi_{p}=\left[\psi_{z} e^{i \phi z}\right] \psi_{0}$ en donde $\psi_{z}$ y $\phi_{z}$

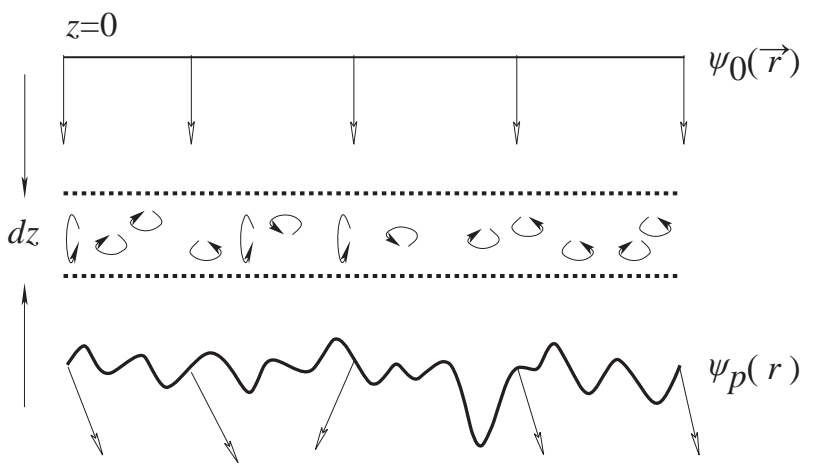

Figura 2. Esquema de la modificación del frente de onda debido a la presencia de una capa turbulenta en la atmósfera.

son respectivamente, la amplitud y la fase a la altura z. El cambio en la fase es consecuencia de las variaciones en el índice de refracción. Para una atmósfera infinita, la fase y el índice de refracción $n$ se encuentran relacionados de la siguiente manera:

$$
\phi_{z}(\vec{r})=k \int_{0}^{\infty} n(\vec{r}, z) d z
$$

en donde $k$ es la magnitud del vector de onda de la onda plana incidente. En el modelo de Kolmogorov, la fase y por lo tanto $n$, se consideran como variables aleatorias con fluctuaciones que presentan una distribución normal, en el sentido estadístico. Por lo tanto, el segundo momento o covarianza espacial de las fluctuaciones en la fase se puede escribir como:

$$
\begin{aligned}
& B_{\phi}(\vec{r})=\left\langle\psi_{z}(\vec{r}+\vec{a}) \psi_{z}^{*}(\vec{a})\right\rangle \\
= & \left\langle e^{i\left[\phi_{z}(\vec{r}+\vec{a})-\phi_{z}(\vec{a})\right]}\right\rangle=e^{-\frac{1}{2} C_{\phi}^{2}}
\end{aligned}
$$

en donde lo vectores $\vec{r}$ y $\vec{a}$ representan la posición de dos puntos sobre el plano perpendicular a la vertical del lugar y $C_{\phi}^{2}$ es la función de estructura en la fase $C_{\phi}^{2}(\vec{r})=\langle| \phi_{z}$ $\left.(\vec{r}+\vec{a})-\left.\phi_{Z}(\vec{a})\right|^{2}\right\rangle$. Sarazin \& Roddier (1990) utilizan en lugar de la fase como variable aleatoria, la derivada direccional del frente de onda perturbado a lo largo de dos direcciones mutuamente perpendiculares $x$ y $y$ sobre el plano del detector. $\operatorname{Si} z(x, y)$ es la función que describe el frente de onda perturbado, la razón de cambio de $z$ en la dirección $x$ es $\alpha(x, y)=\frac{\partial}{\partial x}(x, y)=\frac{\lambda}{2 \pi} \frac{\partial}{\partial x} \phi(x, y)$ y la covarianza de las fluctuaciones en esta variable lo largo de $x$ y $y$ está dada por:

$$
\begin{array}{r}
B_{\alpha}(x, y)=0,145 \lambda^{2} r_{0}^{-5 / 3}\left[\left(x^{2}+y^{2}\right)^{-1 / 6}\right. \\
\left.-\frac{1}{3} x^{2}\left(x^{2}+y^{2}\right)^{-7 / 6}\right]
\end{array}
$$

$\mathrm{B}_{\alpha}(0, y)$ y $\mathrm{B}_{\alpha}(x, 0)$ corresponden a la covarianza longitudinal $\mathrm{y}$ transversal respectivamente. La divergencia para el caso $\mathrm{B}_{\alpha}(0,0)$ no tiene significado físico puesto que en la 
práctica, la covarianza se mide a partir de la varianza del movimiento diferencial en el plano de la imagen (técnica DIMM), la cual usa un telescopio de apertura D. Esta varianza resulta igual a:

$$
\sigma^{2}=2 B_{\alpha}(0,0)=0,358\left(\frac{\lambda}{r_{0}}\right)^{5 / 3}\left(\frac{\lambda}{D}\right)^{1 / 3}
$$

El parámetro de Fried $r_{0}$ en la ecuaciones (3) y (4) corresponde al tamaño de la región sobre la cual el valor cuadrático medio del frente de onda perturbado permanece coherente. Cuanto menor es la varianza del movimiento diferencial de la imagen dual, mayor es el tamaño de esta región. En el modelo de Kolmogorov, r0 en unidades de metros, está definido de la manera siguiente (Lawson \& Carrano, 2006):

$$
\begin{array}{r}
r_{0}=0,185 \times\left(4 \pi^{2}\right)^{3 / 5} \times \\
\times\left[k^{2} \int_{0}^{L} d z\left(\frac{L-z}{L}\right)^{5 / 3} C_{n}^{2}(z)\right]^{-3 / 5}
\end{array}
$$

en donde $\mathrm{k}$ es la magnitud del vector de onda, $\mathrm{L}$ la altura de la atmósfera considerada y $\mathrm{C} 2 \mathrm{n}$ (z) la función de estructura para el índice de refracción. La determinación de r0 requiere el previo conocimiento de la función de estructura como una función de la altura, sin embargo utilizando el DIMM es posible estimar un valor para r0 usando la ecuación (4) y posteriormente el Seeing a través de:

$$
F W H M=0,98 \frac{\lambda}{r_{0}}
$$

en donde FWHM es el Seeing en radianes y $\lambda$ es la longitud de onda para la cual el detector CMOS presenta la máxima eficiencia. Dicha eficiencia depende de la sensibilidad del ISO utilizado durante la adquisición de los videos. Las medidas realizadas por Sigernes (2009) confirman que para un ISO de 1600, la intensidad resultante es igual a 500 $R / \AA$ para una longitud de onda $\lambda=4000 \AA$, en donde $R$ es la reflectancia direccional espectral, una medida del flujo monocromático registrado por el detector en el experimento realizado por el autor. Para el mismo ISO pero en $\lambda=5800 \AA$, el flujo aumenta a $3300 R / \AA$ y finalmente en $\lambda=7000 \AA$ el flujo es $1500 R / \AA$. Por otra parte, valores típicos de $r_{0}=10 \mathrm{~cm}$, conducen a una diferencia en el cálculo del Seeing usando la ecuación 6 , igual a 0,1 " para valores de longitud de onda de 5500 y $6000 \AA$. Este hecho sugiere una contribución muy pequeña al tamaño de la barra de error en las Figuras 4, 5 y 6, por lo tanto y para los objetivos de este trabajo se asume que en la longitud de onda $5500 \AA$ el sensor presenta la máxima eficiencia.

Con el fin de validar los resultados obtenidos con el DIMM, en este trabajo implementamos una metodología alterna para la determinación del Seeing a partir del análisis conjunto de imágenes satelitales y medidas de variables meteorológicas en tierra para la evaluación de la integral en la ecuación (5) y consecuentemente el Seeing usando la ecuación (6).

\section{La técnica Dimm}

Una de las formas más utilizadas para medir el Seeing se basa en el registro continuo del movimiento diferencial de una imagen dual o DIMM por sus siglas en inglés, el cuál se describe en detalle en Sarazin \& Roddier (1990). La idea básica consiste en colocar una máscara de Hartmann en la apertura del telescopio con el objetivo de hacer pasar la luz proveniente de una estrella brillante a través de dos aperturas circulares de diámetro $D$ y separadas una distancia $d$. El resultado es una imagen dual de la estrella en el plano de la imagen. Para garantizar la coherencia se utiliza un prisma recto en una de las aperturas. La separación entre estos dos puntos brillantes varía en escala de tiempo de mili-segundos $(m s)$ y se encuentra relacionada con la distorsión del frente de onda incidente, por lo que se utiliza como una medida indirecta del Seeing. La técnica DIMM consiste en determinar la desviación estándar de la distribución de separación entre dos puntos brillantes a lo largo de dos direcciones mutuamente perpendiculares una de ellas coincidente con la recta que une los centros de los dos orificios en la máscara.

Para el presente estudio se implementó una versión del DIMM levemente diferente sin usar el prisma y en lugar de ello ubicando la cámara de video detrás del foco Cassegrain con el fin de obtener la imagen dual. Si bien, las medidas sin el uso del prisma no pueden considerarse como absolutas, un análisis comparativo de valores relativos de Seeing en los cuatro lugares de la Tabla 1 resulta confiable aún sin el uso del prisma (Boumis, et al. 2001). La metodología consiste en obtener videos de corta duración (15 a $20 \mathrm{~s}$ ) cada 30 minutos durante toda la noche utilizando un tamaño de fotograma de $1920 \times$ 1080 pixel con una cadencia de 30 cuadros por segundo. Consecuentemente, se obtienen entre 450 y 600 imágenes por cada video, correspondiente a variaciones de $33 \mathrm{~ms}$. Posteriormente, usamos nuestro propio código para cargar cada imagen y obtener las coordenadas de los dos puntos brillantes en el plano de la imagen y su separación en pixeles a través de un algoritmo de tipo Flood Fill que implementamos con librerías de Python. Se descartan imágenes con una razón señal a ruido baja debido a cielo parcialmente cubierto o a observaciones con masa de aire superior a dos. La Figura 3 corresponde a las distribuciones de las separaciones entre los dos puntos brillantes en 6 instantes de la noche del 17 de febrero de 2014 en la localidad de Murillo. Debido a la alta humedad en el lugar y con el fin de preservar el DIMM seco, este se mantuvo al aire libre solamente durante el registro de los videos por lo que cada vez la cámara se desenfocó a distancias levemente distintas. Por esta razón, las distribuciones de la figura presentan máximos entre 10 y 35 pixeles. Este hecho no afecta el cálculo del Seeing toda vez que el factor determinante es el ancho de dichas distribuciones y no la localización del máximo. 


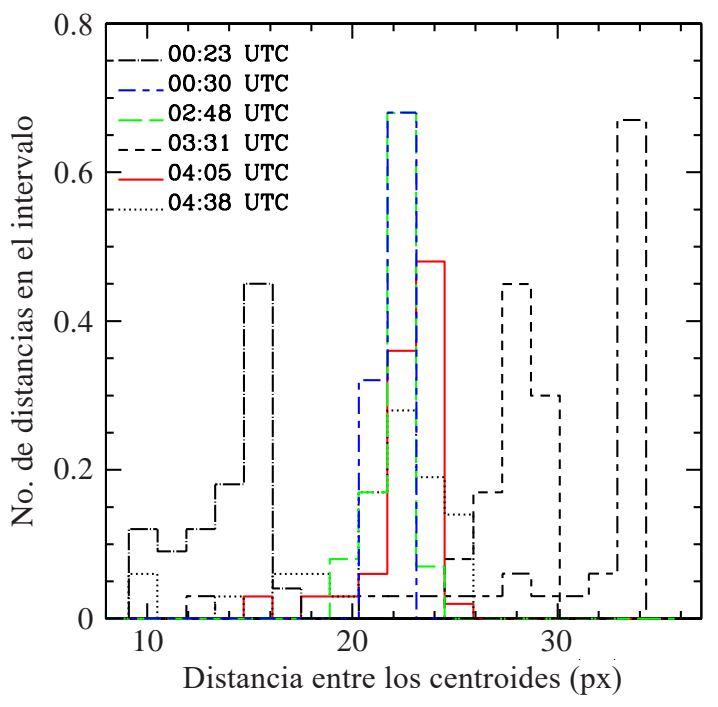

Figura 3. Distribución de la distancia entre las dos aperturas en distintos instantes durante la noche del 17 de febrero de 2014 en Murillo (MUR). La desviación estándar de cada distribución se utiliza para determinar el Seeing en el instante de observación usando las ecuaciones (4) y (6).

La desviación estándar del movimiento diferencial de la imagen a lo largo de las direcciones longitudinal y transversal en el plano de la imagen se denota con $\sigma_{l}$ y $\sigma_{t}$ y está dada por:

$$
\begin{aligned}
\sigma_{l}^{2} & =\left[1-0,541\left(\frac{d}{D}\right)^{-1 / 3}\right] \sigma^{2} \\
\sigma_{t}^{2} & =\left[1-0,811\left(\frac{d}{D}\right)^{-1 / 3}\right] \sigma^{2}
\end{aligned}
$$

en donde $D=4,5 \mathrm{~cm}$ es el diámetro de las aperturas, $d=$ $14,5 \mathrm{~cm}$ su separación y $\sigma$ la desviación estándar total del movimiento diferencial de imagen dada por la ecuación (4). Usando esta ecuación y las expresiones (7) y (8) se obtienen sendos valores longitudinal y transversal para el parámetro de Fried. El Seeing a lo largo de cada una de las direcciones está dado por $F W H M_{l}=0,98 \lambda / r_{0}(t)$ y $F W H M_{l}=0,98 \lambda / r_{0}(t)$ en donde $r_{0}$ se calcula usando la ecuación (4). Una corrección adicional de los valores de Seeing al cenit se realiza a través de la distancia cenital $s$ en el instante de observación, obtenida vía la ascensión recta $(\alpha)$, declinación $(\delta)$ y el instante de observación reportados por el programa de control del telescopio usando la siguiente relación:

$$
s=\cos ^{-1}(\cosh \cos \delta \cos \phi+\operatorname{sen} \delta \operatorname{sen} \phi)
$$

en donde $h$ es el ángulo horario de la estrella observada y $\phi$ la latitud del sitio de observación. El ángulo horario se obtiene a partir del tiempo sidéreo local el cual a su vez se calcula con base en la longitud geográfica y el tiempo sidéreo en Greenwich en el instante de observación. El valor corregido FWHMC dado por $F W H M_{C}=F W H M \times \sec (s)$ se indica en los paneles b) y e) de las Figuras 4, 5 y 6.

\section{Función de correlación atmosférica}

Las fluctuaciones de las variables índice de refracción y temperatura no son independientes. Si $P_{0}$ y $T_{0}$ son respectivamente, la presión y la temperatura en el sitio de observación y $z$ es la altura medida sobre vertical de la atmósfera, las fluctuaciones en ambas variables se encuentran acopladas de la manera siguiente (Roddier, 1981):

$$
C_{n}^{2}(z)=77,6 \frac{P_{0}}{T_{0}^{2}} C_{T}^{2}(z)
$$

por lo tanto, la integral en la ecuación (5) se puede evaluar si se conoce $C_{T}^{2}(\mathrm{z})$ y las variables meteorológicas de forma simultánea. Cavazzani, et al. (2012) han propuesto una metodología para el cálculo de la función de estructura $C_{T}^{2}(z)$ mediante el uso de imágenes satelitales en tres bandas del infrarrojo definiendo una función de correlación atmosférica sobre la vertical del lugar aprovechando que la radiación en cada banda proviene de un altura diferente. En este trabajo se implementa dicha metodología con el objetivo de estimar un Seeing satelital y validar las medidas obtenidas con el DIMM.

Utilizamos datos de archivo del satélite geoestacionario GOES 13 el cual está equipado con instrumentación capaz de capturar imágenes en varias bandas en el infrarrojo. Dado que nuestro propósito es estimar un valor del parámetro de Fried y por lo tanto del Seeing, focalizamos nuestra atención en las bandas B3, B4 y B6 centradas en 6,7, 10,7 y 13,3 $\mu \mathrm{m}$, respectivamente (Erasmus \& Sarazín, 2002). Las imágenes en B4 están afectadas por la emisión y absorción de vapor de agua localizado en nubes con altura del orden de $4 \mathrm{~km}$ mientras que el canal B3 presenta un máximo de transmitancia a una altura entre 8 y $10 \mathrm{~km}$. Las imágenes en el canal B6 proporcionan información de neblina y otras características propias de alturas muy bajas, cercanas a la superficie (Erasmus \& Sarazín, 2002).

La base de datos del satélite GOES es de libre acceso a través de la librería electrónica de NOAA (National Oceanic and Atmospheric Administration) en un formato especial denominado GVAR. Para cada fecha de interés se selecciona una región de la imagen que contenga a Colombia y se descargan imágenes nocturnas en los tres filtros B3, B4 y B6, con una cadencia aproximada de media hora, comenzando a las 00:15:19 UTC y finalizando a las 09:45:19 UTC. Posteriormente usamos las librerías idl proporcionadas por NOAA con el fin de convertir radianza instrumental a temperatura de brillo para cada lugar de interés y en cada canal infrarrojo, asumiendo que la radiación es de cuerpo negro. Notamos estos valores de temperatura en cada banda y en el instante $i$, como $T_{B 3, \mathrm{i}}$, $T_{B 4, i}$ y $T_{B 6, i}$, respectivamente.

La resolución de las imágenes es de $4 \times 4 \mathrm{~km}$ en las tres bandas pero en la Figura 1 hemos utilizado una interpolación de Delanuay del mapa de temperatura, reduciendo 

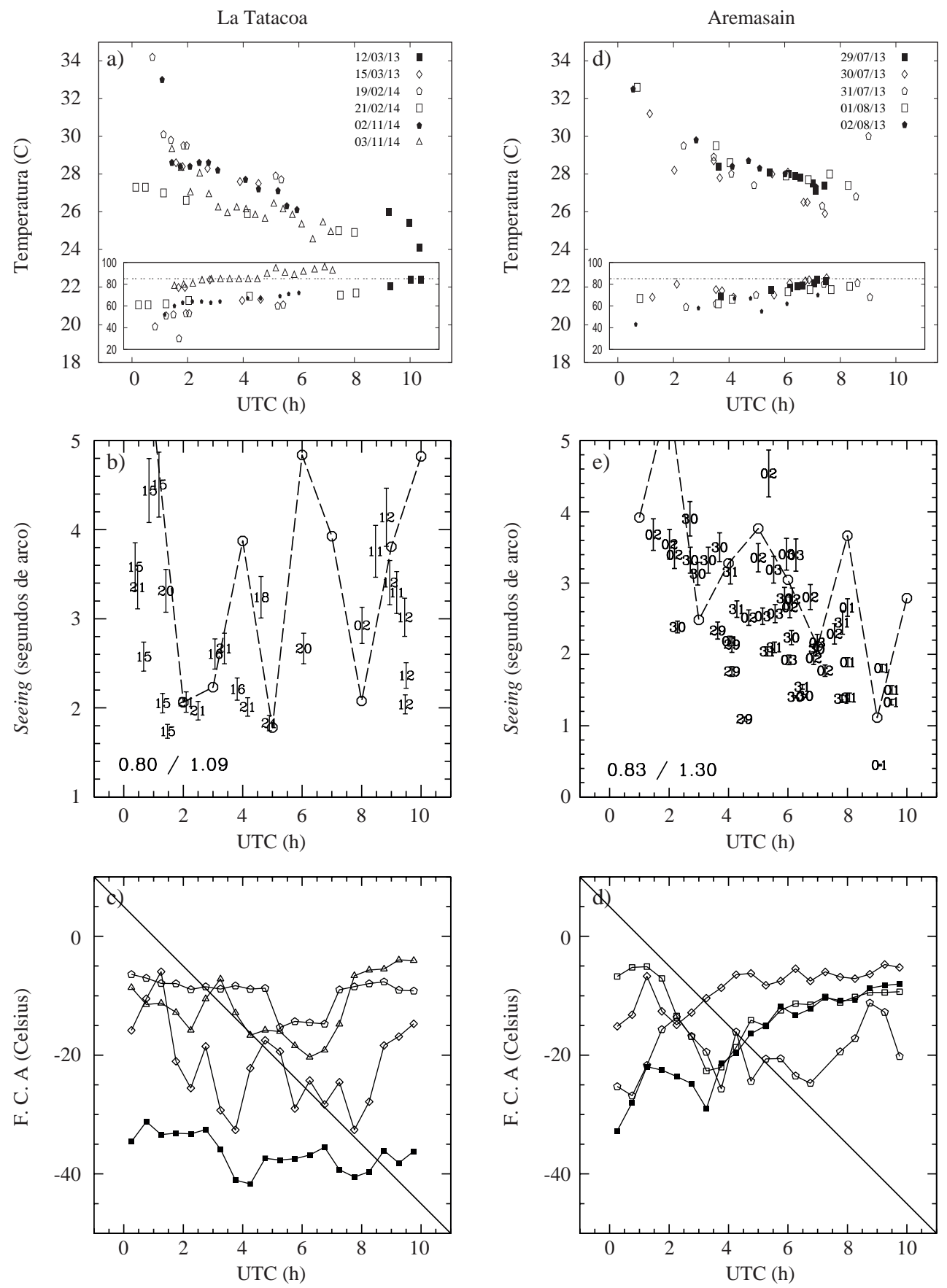

Figura 4. Medidas de la calidad del cielo en La Tatacoa (paneles a, b y c) y en Aremasain (paneles d, e y f). En a) y d) se muestran los valores de temperatura y humedad a lo largo de cada noche (la línea a trazos en la figura interior corresponde al $85 \%$ de humedad). Las medidas de Seeing en los paneles b) y e) se representan con símbolos numéricos asociados a la noche de observación indicada en a) y en d). Los paneles c) y f) corresponden a la función de correlación atmosférica $F C A=T_{B 3}-\left(T_{B 4}-T_{B 6}\right)$ en los mismos instantes durante la noche. En cada instante, el promedio de FCA se utiliza para la determinación del Seeing satelital el cual se indica con línea a

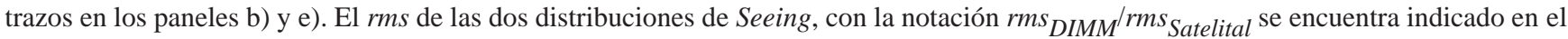
extremo inferior izquierdo de dichos paneles.

la resolución a $17 \times 25 \mathrm{~km}$ por pixel. Esta interpolación permite calcular valores de temperatura de brillo en los tres canales en los lugares más cercanos a las coordenadas de los sitios en la Tabla 1 con una precisión inferior al 10\%.
Siguiendo la metodología descrita en Cavazzani, et al. (2012), se define la Función de Correlación Atmosférica (FCA) en el instante $i$ de la siguiente manera:

$$
F C A_{i} \equiv T_{B 3, i}-\left(T_{B 6, i}-T_{B 4, i}\right)
$$


puesto que esta definición proporciona una temperatura de brillo en las tres bandas combinadas con la ventaja que permite registrar variaciones en la temperatura debido a efectos atmosféricos principalmente turbulencia en baja altura, cerca de la superficie. Los valores para $F C A_{i}$ obtenidos en los lugares visitados se indican en los paneles c) y f) de las Figuras 4 y 5 con símbolos coincidentes con las fechas que aparecen en los paneles a) y d) de la misma figura.

Una vez se conoce el valor de FCA para cada instante durante la noche en cada una de las fechas indicadas en la última columna de la Tabla 1 se procede a evaluar el valor medio $<F C A>_{i}$ en cada instante usando los datos de todas la noches de manera conjunta. Posteriormente se obtiene la variación relativa calculando la cantidad $F C A-<F C A>i$ en donde $<F C A>i$ representa el valor medio de la función de correlación en el instante $i$. Finalmente se calcula el Seeing satelital en radianes, usando la siguiente ecuación (Cavazzani, et al. 2012):

$$
\begin{array}{r}
F W H M_{i}=0,58 \lambda^{-1 / 5} \times \\
\times\left(4 \pi^{2} \Lambda(z) \frac{\left|F C A_{i}-<F C A>_{i}\right|}{z}\right)^{-3 / 5}
\end{array}
$$
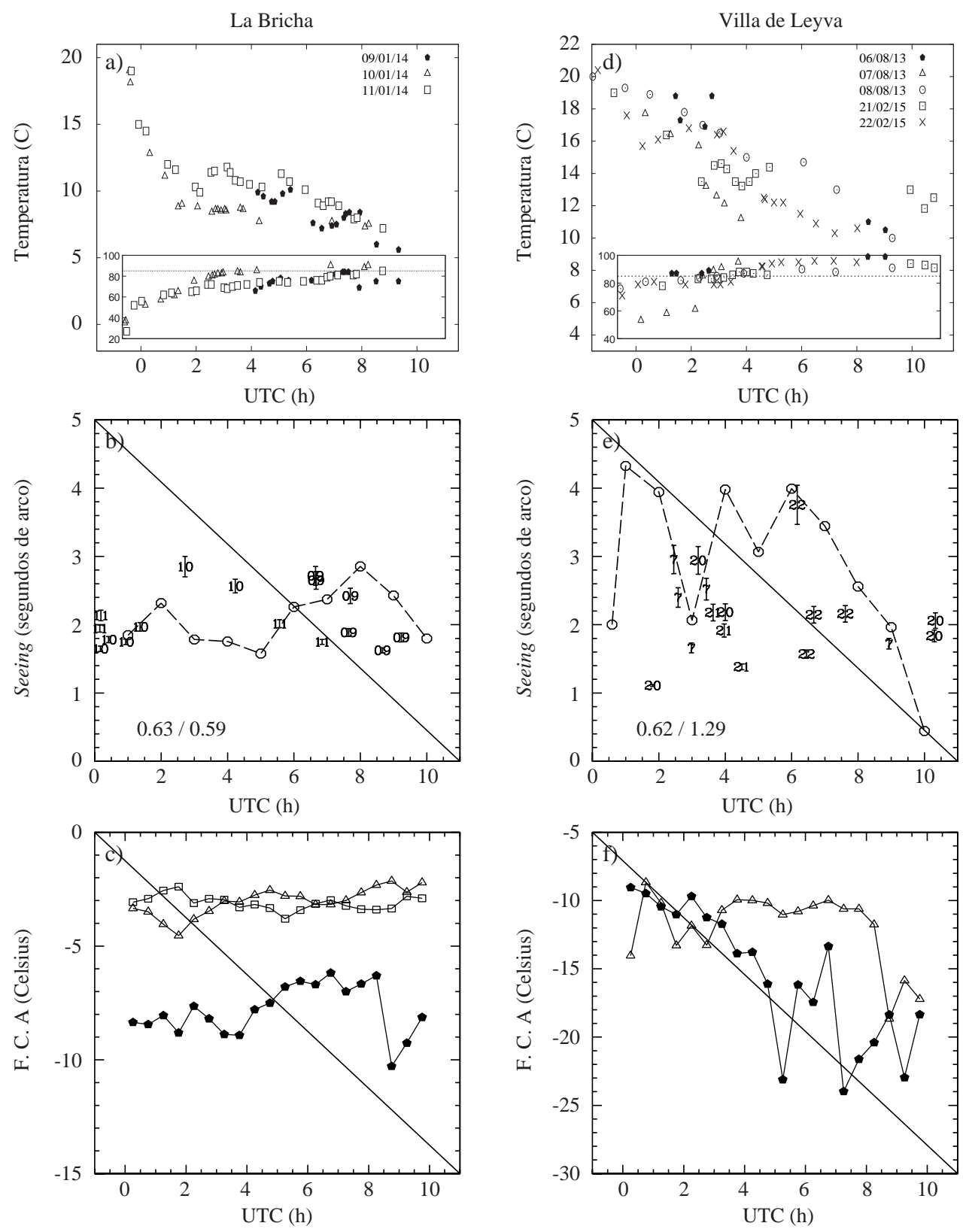

Figura 5. Medidas de la calidad del cielo en La Bricha (paneles a, b y c) y en Villa de Leyva (paneles d, e y f). Los símbolos son idénticos a los de la Figura 4. 

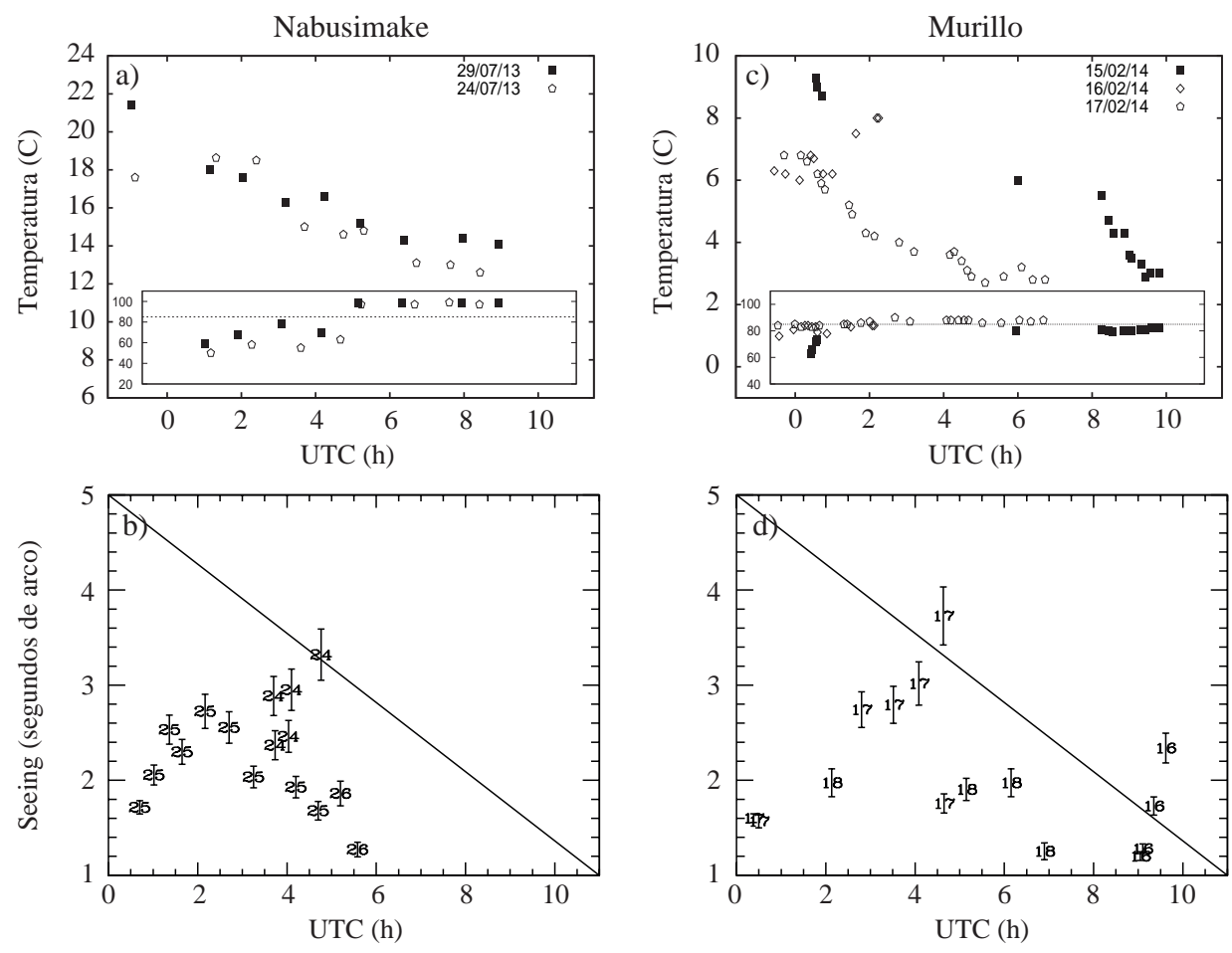

Figura 6. Medidas de la calidad del cielo en Nabusimake (paneles a y b) y en Murillo (paneles c y d).

en donde $\Lambda(z)$ es un parámetro que depende de $T_{0}, P_{0}$, de la altura del sitio de observación y débilmente de la distancia cenital del satélite toda vez que GOES13 es geoestacionario. Cavazzani, et al. (2012) utilizan $\Lambda(z)=10^{-12}$ con el fin de minimizar las diferencias con datos simultáneos obtenidos en los observatorios Cerro Paranal en Chile y en Roque de los Muchachos en las Islas Canarias. Debido a la baja estadística de las medidas obtenidas con el DIMM, preferimos calcular este parámetro para Aremasain, La Tatacoa, La Bricha y Villa de Leyva, basados en nuestras medidas de temperatura in-situ y valores de presión obtenidos de la literatura para posteriormente realizar la comparación con los datos DIMM. En la columna 6 de la Tabla 1 se encuentran los valores obtenidos para $\Lambda(z)$, los cuales están en el orden de magnitud de aquellos predichos por un modelo empírico para $C_{n}^{2}(z)$ desarrollado por Parenti \& Sasiela (1994).

Los resultados obtenidos para el Seeing satelital utilizando esta metodología se representan con una línea a trazos en los paneles b) y c) de las Figuras 4 y 5 . Se observan fluctuaciones hasta de 2 " en intervalos de tiempo inferiores a dos horas. Los datos obtenidos con el DIMM se encuentran por debajo de la predicción satelital, hecho que puede estar relacionado con la ausencia de prisma. Desenfocar genera mayor incertidumbre en el cálculo de los centroides en comparación al DIMM usual que involucra el prisma. Cuantificamos las diferencias entre las medidas DIMM con la predicción satelital, implementando un análisis $\chi^{2}$ para cada lugar. Las diferencias son menores en La Tatacoa $\left(\chi^{2}=0,54\right)$ y en La Bricha $\left(\chi^{2}=\right.$ $0,70)$, mientras que en Aremasain se obtiene $\chi^{2}=1,81$ y en Villa de Leyva $\chi^{2}=2,77$.

Si bien el número de medidas con el DIMM es extremadamente bajo en los cuatro lugares, la dispersión es similar a aquella observada en los datos obtenidos con imágenes satelitales. El valor medio cuadrático ( $r m s$ en adelante) de ambas series, con la notación $r m s_{D I M M} / r m s_{\text {Satelital }}$, se encuentra en la parte inferior de los paneles b) y e) de las Figuras 4 y 5 y 6 . Es particularmente interesante que para La Bricha se obtiene $0,63^{\prime \prime} / 0,59^{\prime \prime}$ equivalente a una diferencia del 5\%.

En La Tatacoa se observa una mayor dispersión 0,80"/1,09" correspondiente a una diferencia del $26 \%$. Los datos de Aremasain $0,83^{\prime \prime} / 1,30^{\prime \prime}$ conducen a una diferencia del $36 \%$ y en Villa de Leyva se obtiene la máxima diferencia entre las predicciones satelitales y las medidas in-situ con $0,62^{\prime \prime} / 1,29^{\prime \prime}$ equivalente a una diferencia de $51 \%$. Este hecho confirma la estabilidad atmosférica observada durante dos de las tres noches en la vereda La Bricha, situación particular única durante la campaña que permite inferir que los dos métodos son comparables.

Para los propósitos de comparación del presente trabajo, consideramos suficiente el hecho que en una atmósfera estable como en La Bricha el rms de ambos valores de Seeing difiera en un 5\%. Por lo tanto, utilizamos las medidas realizadas con el DIMM en los diferentes lugares como la variable fundamental en el análisis comparativo. 

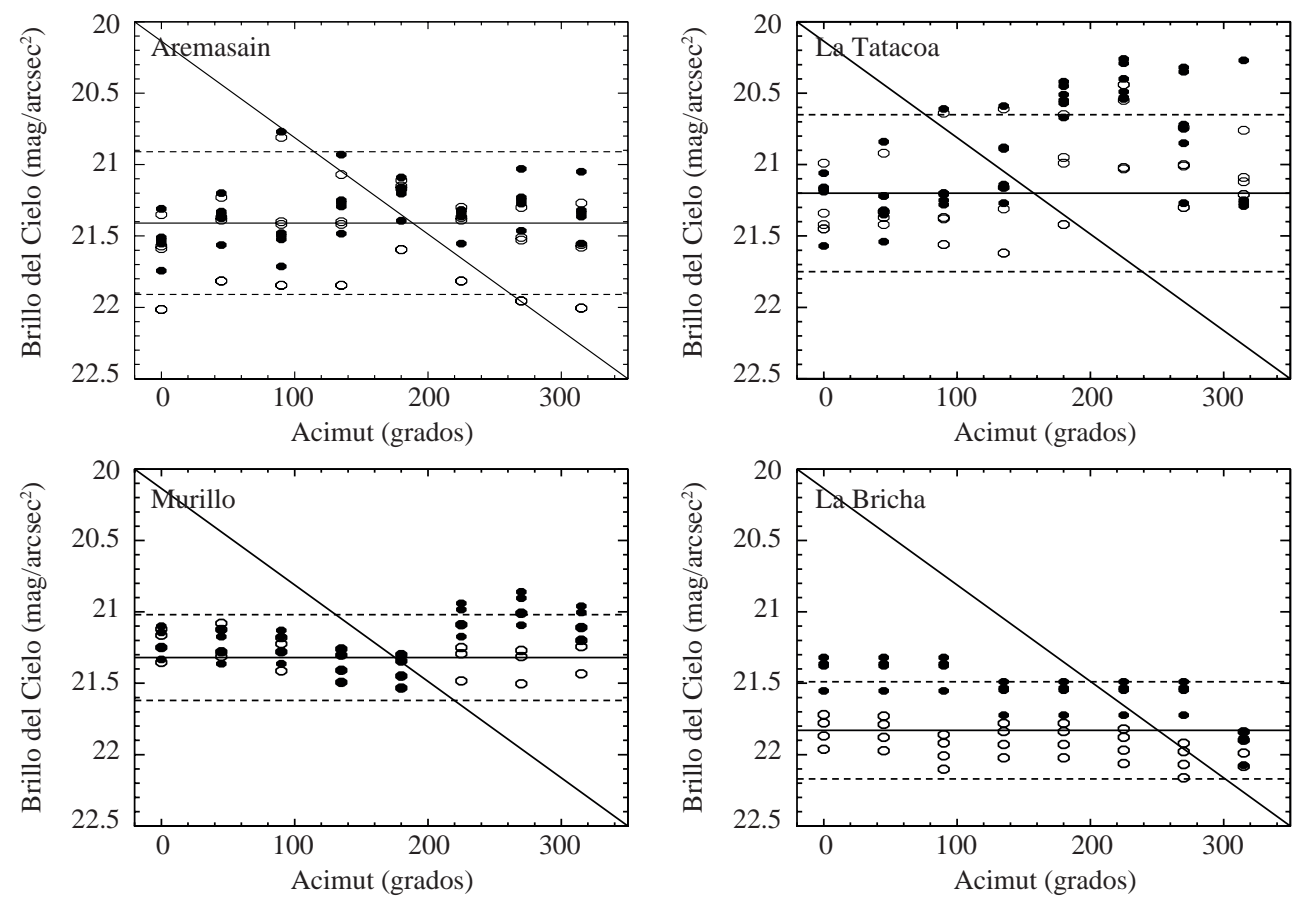

Figura 7. Brillo del cielo obtenido al apuntar el SQM sobre el horizonte (símbolos color blanco) y a una altura aproximada de 45 grados (símbolos color negro).

\section{Descripción de los sitios}

En esta sección se describen las propiedades de cada sitio. Es importante anotar que nuestras visitas fueron esporádicas y de corta duración por lo tanto no pueden considerarse como representativas del lugar. Sin embargo, la información recolectada en todos los lugares puede compararse puesto que el instrumental utilizado en todas las misiones fue el mismo y la metodología idéntica. Dicha comparación permite identificar el sitio con menos turbulencia integrada toda vez que un criterio basado en extinción atmosférica no es posible con los datos disponibles en este trabajo.

\section{La Tatacoa}

Es un bosque tropical seco localizado a 450 metros de altura entre las cordilleras Central y Oriental que se extiende sobre un área erosionada de 330 kilómetros cuadrados. Se realizaron 3 expediciones cortas en marzo de 2013, en febrero y noviembre de 2014 con cielo parcialmente cubierto la mayor parte del tiempo excepto durante el comienzo de la noche y con valores de humedad y temperatura al comienzo de la noche, del orden del $60 \%$ y $30^{\circ} \mathrm{C}$ respectivamente. La temperatura disminuye rápidamente hasta estabilizarse alrededor de $\operatorname{los} 26^{\circ} \mathrm{C}$ entre las 2:00 y 7:00 horas en UTC, para luego exhibir una fuerte disminución hacia el final de la noche como se observa en el panel a) de la Figura 4.

Debido a su baja altitud y a estar localizada en el valle entre dos cordilleras (ver Figura 8), La Tatacoa recibe durante la noche el aire seco y frio proveniente de las montañas. En condiciones de cielo despejado, el aire seco en sitios vecinos con alturas entre 1000 y 2000 metros, sobre las cordilleras, no absorbe eficientemente la radiación térmica infrarroja emitida por la superficie por lo que se enfría, estimulando su descenso sobre las zonas planas del valle del Río Magdalena. La Tatacoa se llena de aire frio en la madrugada. De hecho los valores de humedad son superiores a $85 \%$ y la temperatura aproximadamente constante de $26^{\circ} \mathrm{C}$ entre 2:00 y 8:00 UTC.

Valores de Seeing obtenidos con el DIMM presentan una dispersión con un $r m s=0,80^{\prime \prime}$. La barra de error en el panel b) de la Figura 4 es 0,5" para valores de Seeing superiores a $3^{\prime \prime}$ pero disminuye a $0,2^{\prime \prime}-0,3^{\prime \prime}$ para valores de Seeing por debajo de esta cantidad. Este resultado se encuentra en concordancia con predicciones del modelo de Kolmogorov en el cual las variaciones longitudinales son del orden de 1,5 veces mayores que aquellas en la dirección transversal al tiempo que confirma el alto grado de turbulencia en la atmósfera del lugar, hecho relacionado con la baja altura. El brillo del cielo medido en regiones claras, sobre el cenit, a $45^{\circ}$ de altura (círculos de color blanco) y sobre el horizonte (círculos de color negro). En la Figura 7 se muestran los resultados correspondientes al promedio de todas las noches. La línea sólida representa el valor medio de brillo del cielo en el cenit igual a $21,2 \mathrm{mag} \times$ segundos de $\mathrm{arco}^{-2}$ en tanto que la línea a trazos corresponde al valor $3 \sigma$ alrededor del promedio. Se observa contaminación lumínica proveniente de Neiva en dirección sur con magnitudes por encima de este umbral. 
La Tatacoa es un lugar de fácil acceso por ser un sitio turístico en el Departamento del Huila con un creciente interés en la Astronomía motivado por su clima cálido y seco durante el día. Si bien, las condiciones del lugar son apropiadas para la observación del cielo al comienzo de la noche, el cubrimiento de nubes y el porcentaje de humedad aumentan considerablemente durante la madrugada.

\section{Aremasain}

Este lugar localizado en el departamento de La Guajira, a $24 \mathrm{~km}$ en dirección sureste de Rioacha tiene como principal característica la baja humedad. Visitamos el sitio entre el 29 de julio y el 5 de agosto de 2013 y solamente registramos valores de humedad superiores a $80 \%$ durante el alba. El cubrimiento nocturno de nubes se presenta variable $\mathrm{y}$ modulado por fuertes ráfagas de viento de hasta $20 \mathrm{~km} / \mathrm{h}$ especialmente durante la noche del 30 de julio en la cual el cielo estuvo completamente cubierto desde las 7:20 UTC. La medida del brillo del cielo se realizó al comienzo de las noches con el fin de evitar interferencia con la Luna. El promedio del brillo del cielo durante las ocho noches es 21,41 mag $\times$ segundos de arco $^{-2}$, muy similar al registrado en La Tatacoa como se indica en la Figura 7.
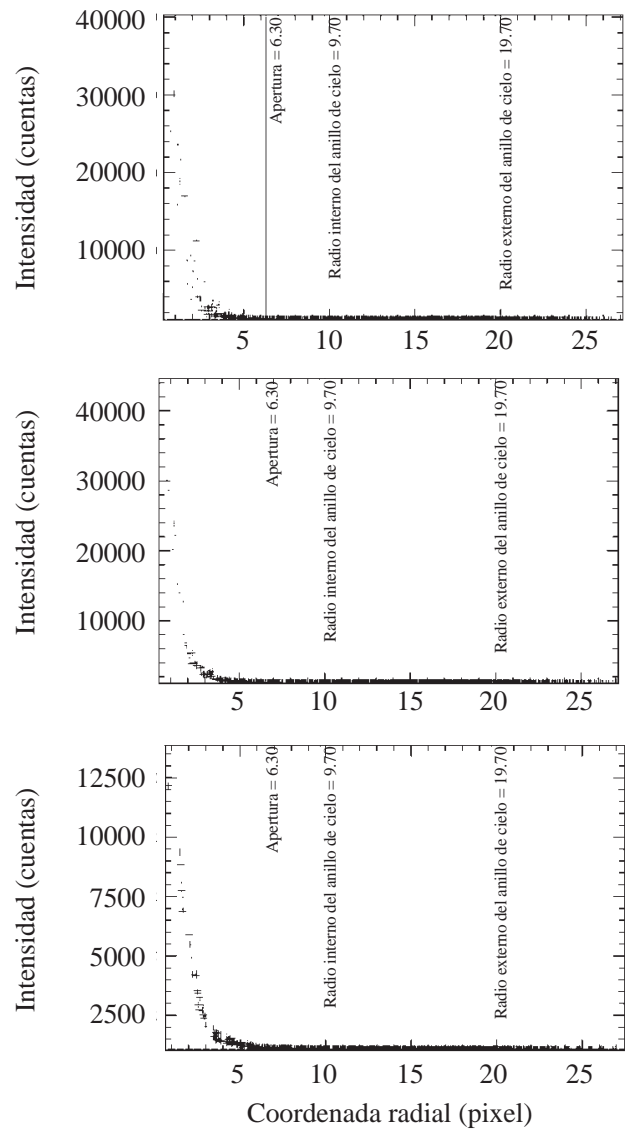

Figura 8. Intensidad instrumental (en ADUs) como función de la coordenada radial en los filtros B (panel superior), V (panel del medio) e I (panel inferior), para la estrella Vega la noche del 30 de julio de 2013 a las 06:54 UTC.
El Seeing en Aremasain es altamente variable, con un rms = $0,83^{\prime \prime}$. La baja humedad del sitio permitió realizar un mayor número de medidas de Seeing y de imágenes fotométricas en comparación con los otros lugares. Si bien, la fracción de cielo claro durante la noche es similar a otras regiones del país, la presencia de vientos y el relativo aislamiento de grandes cumbres, hacen de Aremasain el lugar con cielo más despejado comparativamente con los otros cinco sitios analizados en este estudio. El acceso a Aremasain es desde Rioacha. El lugar se ubica en una zona árida con muy poca contaminación lumínica pero con ocurrencia de ráfagas de viento periódicas e intensas $(>20 \mathrm{~km} / \mathrm{h})$ las cuales incrementan los valores de turbulencia integrada y disminuyen el tiempo de vida del aluminizado de los espejos del telescopio.

Con el fin de determinar el coeficiente de extinción atmosférico se utilizaron entre 6 y 8 imágenes CCD por noche de la misma estrella estándar en tres filtros fotométricos. La metodología consistió en obtener la magnitud de la estrella en cada filtro y a masas de aire distintas. El procedimiento detallado se encuentra descrito en Rufener (1986) Brevemente, si $m_{0}$ denota la magnitud de la estrella obtenida antes de cruzar la atmósfera de la tierra y s la distancia cenital en el instante de observación la cual está relacionada con la masa de aire en dicho instante a través de $\sec (s)$, entonces la magnitud observada $m$ en la longitud de onda $\lambda_{0}$ está dada por la relación de Bouguer:

$$
m=m_{0}+k\left(\lambda_{0}\right) \times \sec (s)
$$

en donde $k\left(\lambda_{0}\right)$ es el coeficiente de extinción en unidades de magnitud/masa de aire. Los valores de $\lambda_{0}$ para $B, V$ e $I$ son 430,520 y $800 \mathrm{~nm}$ respectivamente. Los filtros utilizados tienen un espesor de $1 \mathrm{~mm}$, adecuados para el uso en la cámara SBIG ST-402, con una respuesta equivalente a la de los filtros Bessel fotométricos estándar (Bessel, 1990) con excepción al filtro I el cuál presenta un fuerte corte por encima de $1000 \mathrm{~nm}$ en comparación al filtro Bessel estándar lo que disminuye la razón señal a ruido de las imágenes en este filtro, como se observa en la Figura 8.

El detector Kodak KAF-0402ME de la cámara SBIG ST402 , consiste en una red de $765 \times 510$ pixeles cada uno con un tamaño de $9 \times 9 \mu \mathrm{m}$, con una eficiencia cuántica máxima de $85 \%$ alrededor de $656,3 \mathrm{~nm}$ y un ruido de lectura de 17 electrones RMS. El rango dinámico del detector es $76 \mathrm{~dB}$ y su temperatura se regula en pasos de $0,1^{\circ} \mathrm{C}$ hasta $-35^{\circ} \mathrm{C}$ por debajo de la temperatura ambiente.

El tratamiento de las imágenes se realizó en el paquete CCDPROC del programa IRAF usando la metodología estándar de sustracción de imagen de corriente en oscuro o Dark y división entre una imagen de campo plano o Flat obtenida esta 'ultima, a partir de la mediana de un conjunto de 20 imágenes del cielo libre de estrellas adquiridas al comienzo de la noche. Las imágenes de campo plano se 
obtienen con tiempos de exposición de 10 segundos para el filtro $I, 20$ segundos para el filtro $V$ y 60 segundos para el filtro $B$.

Las magnitudes instrumentales en cada uno de los filtros $B$, $V$ e $I$ fueron determinadas usando el paquete DAOPHOT del programa IRAF-Image Reduction and Analysis Facility (NOAO). Este valor instrumental junto con la masa de aire del instante de observación, permiten obtener el coeficiente de extinción usando la ecuación (13). El primer paso es definir un radio de apertura de acuerdo con el Seeing obtenido de las medidas hechas con el DIMM. Se utiliza una apertura igual 6,3 pixeles equivalente a 1,5FWHM, para todas las imágenes toda vez que con este valor se asegura que la mayor parte de la luz proveniente del objeto se ubique dentro de la apertura sin incluir en ella demasiado ruido del cielo de fondo. En la Figura 8 se ilustra la dependencia de la intensidad de la señal con la coordenada radial para la estrella Vega durante la noche del 29 de julio en Aremasain. La contribución del cielo se descontó de la señal restando de esta el flujo contenido en un anillo de cielo con centro en la estrella y con un radio interno del 10 pixeles y un espesor de 5 pixeles. La conversión de pixel a longitud de arco para la configuración SBIG-402 con el telescopio en F/10 es 0,66" /pixel por lo que el radio interno del anillo de cielo mayor que el FWHM del instante de observación. Las magnitudes instrumentales se obtienen a través de la siguiente relación:

$$
m=m_{p c}-2,5 \times \log \left(\frac{F}{t}\right)
$$

en donde $F$ es igual al flujo instrumental aparente de la estrella, es decir sin la contribución del cielo, $t$ es el tiempo de exposición y $m_{p c}=18,0 \mathrm{mag}$ es la magnitud de referencia o punto cero de la escala instrumental. Los tiempos de exposición para una estrella $A 0$ como $V$ ega son $15 s$ en $I$, $25 s$ en $V$ y $70 s$ en el filtro $B$.

Se calculan tres valores de masa de aire $(M A)$ para cada imagen en tres instantes durante la observación, al comienzo, en la mitad y al final de la misma, usando la relación: $M A$ $=\sqrt{ } s^{2}+2 H+11$, en donde $\mathrm{s}$ es la distancia cenital, $H=$ $2,93 \times 10^{-2} T \mathrm{~km}$ es un factor de escala atmosférico y $T$ es la temperatura en el entorno del telescopio en el instante de observación (Allen, 1973). Con estos tres valores de masa de aire se obtiene un valor medio ponderado dando mayor peso a la observación hecha durante el instante medio (Stetson, 1988).

En la Figura 9 se observa el consolidado de las magnitudes instrumentales obtenidas en este lugar para la totalidad de las noches. Si bien existe un faltante de masa de aire en el intervalo 2.5-3.5, se observa una tendencia clara de disminución del brillo instrumental con el incremento de la masa de aire. $\mathrm{Al}$ realizar un ajuste por mínimos cuadrados, excluyendo observaciones con masa de aire superior a tres, se obtienen los valores para el coeficiente de extinción y para el punto cero instrumental en cada filtro que aparecen en la Tabla 2. Los errores en ambos parámetros están dados por el ajuste lineal realizado. El valor cuadrático medio de los residuales obtenidos se indica en la cuarta columna y no supera el $30 \%$. El error que se obtiene en el coeficiente de extinción está en el orden de la décima de magnitud por masa de aire y aquel para el punto cero instrumental es 0,22 magnitudes en el filtro $B$ y levemente mayor para los filtros restantes.

\section{Murillo}

Murillo es un municipio del departamento de Tolima, localizado a una altura de 3600 metros sobre el nivel del mar y a $10 \mathrm{~km}$ en dirección sureste del Nevado del Ruíz (5321 m). Visitamos la Vereda la Cabaña, un sitio ubicado en la periferia del Parque Nacional de los Nevados a 25 $\mathrm{km}$ del Otún, durante las noches del 15, 16 y 17 de febrero de 2014. Durante las dos primeras noches las condiciones fueron de cielo parcialmente cubierto pero durante la 'ultima el cielo se despejó aunque con una elevada humedad, mayor a $97 \%$ durante toda la noche. Con el fin de evitar la condensación del vapor de agua sobre la óptica del DIMM, este se llevó a cielo descubierto solamente durante las mediciones de Seeing, las cuales se realizaron con una cadencia de media hora.

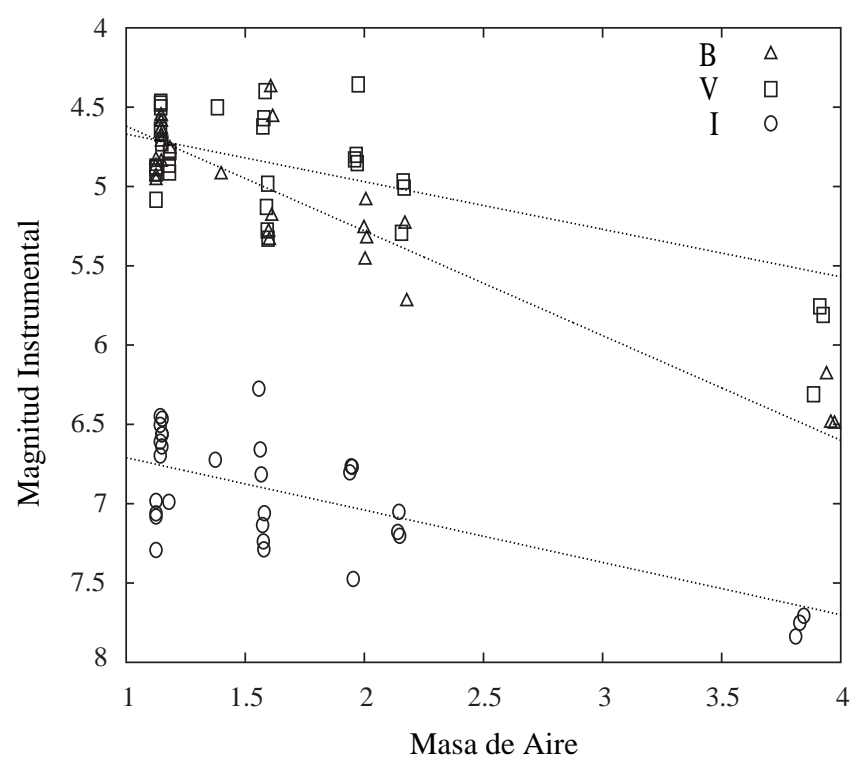

Figura 9. Magnitud instrumental en tres filtros fotométricos en función de la masa de aire de la estrella Vega, en el sitio Aremasain. Los datos corresponden a la totalidad de las noches en este lugar.

Tabla 2. Parámetros fotométricos en Aremasain.

\begin{tabular}{cccc}
\hline Filtro & $k\left(\lambda_{0}\right)$ & $m_{0}$ & $r m s$ \\
\hline B & $0,66 \pm 0,11$ & $3,96 \pm 0,17$ & 0,22 \\
V & $0,30 \pm 0,13$ & $4,37 \pm 0,21$ & 0,26 \\
I & $0,33 \pm 0,15$ & $6,38 \pm 0,23$ & 0,29 \\
\hline
\end{tabular}


Durante las noches del 17 y 18 de febrero de 2014 los valores del Seeing en Murillo se encuentran entre 1" y 4" con notable variabilidad sobre todo la noche del 17 cuando se observan las máximas diferencias entre las componentes transversal y longitudinal en el movimiento diferencial de imagen. La elevada humedad superior al 97\% entre 2:00 y 6:00 UTC incrementa el tamaño de la fuente puntual por lo tanto, los valores se muestran particularmente altos.

El valor medio del brillo del cielo durante las cuatro noches es 21,32 mag× segundos de arco $^{-2}$ con una dispersión menor a la observada en lugares de altura similar como Macaravita. A pesar de su localización en el sector rural del municipio de Murillo, la vereda la Cabaña es un sitio de fácil acceso a través de una vía terciaria. No obstante el lugar es bastante húmedo. La humedad es considerablemente alta superando el $90 \%$ con exceptuando la noche del 15 de febrero en donde registramos $67 \%$ al comienzo de la noche, pero con un aumento rápido hasta estabilizarse en $97 \%$ durante la madrugada y el alba. Por esta razón, instrumentación en el infrarrojo no es recomendable en este lugar.

\section{Nabusimake}

Es un resguardo indígena, centro importante de reuniones de la comunidad Arhuaca. Se encuentra localizado a $40 \mathrm{~km}$ al suroriente del pico Cristóbal Colón (5770 m) en la Sierra Nevada de Santa Marta. Visitamos el lugar las noches del 20 al 26 de julio de 2013 con el objetivo de realizar un ascenso a la cara Nororiental de la Sierra en donde se encuentran lugares con hasta 126 noches despejadas por año. Sin embargo, estos sitios son de gran relevancia espiritual para la comunidad indígena local y por lo tanto el acceso no es fácil. Por esta razón se realizaron las medidas de Seeing y de extinción en Nabusimake a una altitud de 2000 metros y distante $35 \mathrm{~km}$ del Sitio 1 reportado por Pinzón, et al. (2015). El lugar tiene horizonte oriental despejado a pesar de encontrarse en las estribaciones de la Sierra Nevada de Santa Marta.

La humedad máxima en Nabusimake oscila entre 59-68\% al comienzo de la noche pero sube rápidamente y después de media noche supera el $85 \%$. Se registran vientos esporádicos con velocidad de hasta $15 \mathrm{~km} / \mathrm{h}$. La observación de estrellas estándar a distintas masas de aire se realizó durante el comienzo de las noches en condiciones de elevada humedad, lo cual afectó considerablemente la calidad de los datos fotométricos. El Seeing presentó los máximos valores entre 3" y 4" durante la noche del 24 de julio de 2013, mientras que durante la noche del 25 de julio se registró un Seeing inferior a 2" después de las 03:00 UTC con diferencias entre las componentes longitudinal y transversal menores a $0,2^{\prime \prime}$.

\section{Macaravita}

Es un municipio localizado entre la frontera que divide los departamentos de Boyacá y Santander a una distancia de $50 \mathrm{~km}$ de los picos nevados de la Sierra Nevada del Cocuy,
Guicán y Chita. Visitamos dos sitios en Macaravita entre el 5 y el 11 de enero de 2014, La vereda la Bricha y el Alto de los Rayos. Este 'ultimo a una altura de 3000 metros presentó unas condiciones extremas de humedad con un promedio diurno de $62 \%$ y con valores de $92 \%$ desde el comienzo de la noche. Por esta razón, no se obtuvieron datos fotométricos para este lugar y se realizaron solamente dos medidas con el DIMM debido al mal tiempo. El valor medio de dichas medidas es $1,8^{\prime \prime}$. La visita tuvo lugar durante 3 noches, la primera con 13 horas de lluvia y las otras dos con cielo despejado pero con humedad de $97 \%$.

Visitamos también la vereda La Bricha localizada $6 \mathrm{~km}$ hacia el este del Alto de los Rayos, en donde las condiciones de humedad fueron distintas. Este lugar se encuentra en una región más seca a 2600 de altura sobre el valle del río Nevado entre los departamentos de Boyacá y Santander (ver Figura 10). El comienzo de la noche estuvo marcado por una humedad de $60 \%$ como se indica en el panel a) de la Figura 6, con un posterior incremento hasta $82 \%$ alrededor de las 7:00 horas UTC. Durante las noches del 9 y 11 de enero de 2014, se registró una disminución de la humedad a las 9:00 UTC con valores de hasta 70\%. Destacamos este comportamiento de la humedad toda vez que éste no fue observado en ningún otro lugar de los sitios analizados.

El Seeing en La Bricha presenta valores inferiores a 2" durante el comienzo y el final de la noche. Se observa un incremento hacia las 3:00 UTC cuando se registran valores cercanos a 3", especialmente para la noche del 10 de enero de 2014. La variabilidad es baja en comparación con los otros sitios visitados durante la campaña con un $r m s=$

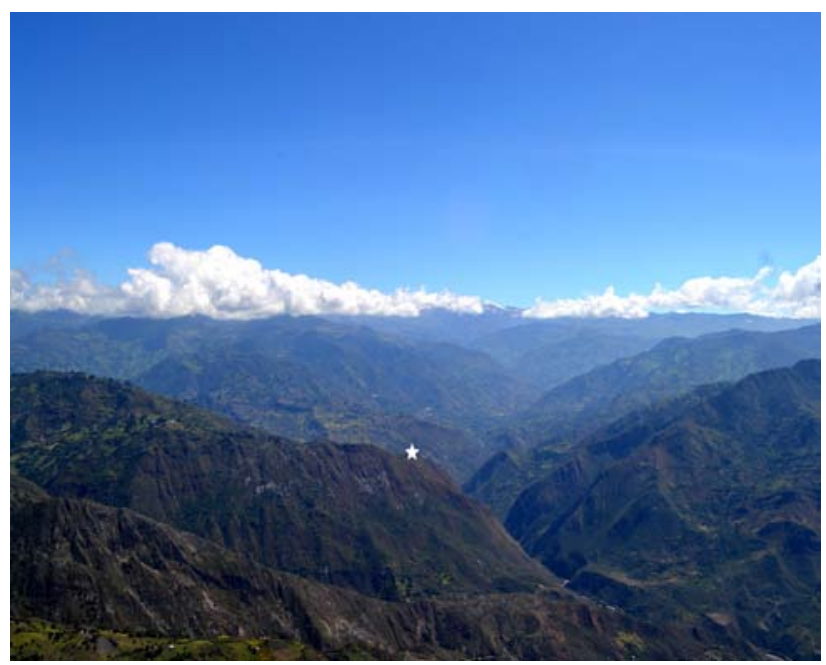

Figura 10. Región de Macaravita en Santander, divisada desde el Alto de los Rayos. Los picos nevados de la Sierra Nevada del Cocuy, Guicán y Chita en Boyacá, se encuentran al fondo, hacia el oriente, cubiertos parcialmente por nubes ligeras. La estrella indica la localización de la vereda La Bricha, el lugar más apropiado para la ubicación de instrumentación astronómica en el rango óptico, según el análisis comparativo presentado en este trabajo. 
$0,63^{\prime \prime}$. La validación de los datos del DIMM realizados con el método de imágenes satelitales conduce a la diferencia porcentual del $5 \%$, la más baja registrada durante la campaña, sugiriendo mayor estabilidad en los parámetros atmosféricos, en comparación con los otros lugares que se visitaron. El valor promedio del brillo del cielo para las tres noches es $21.83 \mathrm{mag} \times$ segundos de $\operatorname{arco}^{-2}$ como se muestra en la Figura 7.

El acceso a La Bricha es por Macaravita a través una vía terciaria. La Bricha es un lugar poco poblado con un horizonte abierto y con humedad inferior a $85 \%$ la mayor parte de la noche. La comunidad gubernamental del municipio al cual pertenece la vereda, manifiesta interés en un proyecto de infraestructura astronómica en la región.

\section{Villa de Leyva}

Es un municipio de Boyacá localizado en la Provincia de Ricaurte a $40 \mathrm{~km}$ al oeste de Tunja. Visitamos el Museo Paleontológico de Villa de Leyva el cual se encuentra a $1.5 \mathrm{~km}$ del centro de la ciudad, las noches el 6 a 12 de agosto de 2013 y entre el 19 y el 22 de febrero de 2015. El cielo se presentó parcialmente cubierto de nubes durante nuestra visita y la humedad particularmente alta debido a la cercanía del lugar con sector de la Cuchilla de Morro Negro, una cadena montañosa que atraviesa el departamento de Boyacá en dirección nor-oriental y está localizada a $5 \mathrm{~km}$ de Villa de Leyva. Los valores de temperatura en el Museo Paleontológico son levemente mayores en promedio a los registrados en sitios de con altura similar como la vereda La Bricha. Sin embargo, el cubrimiento de nubes durante las noches de la visita al lugar, impidió el registro de datos fotométricos.

Las medidas de Seeing en el Museo Paleontológico presentan valores inferiores a 3 " y elevada variabilidad toda vez que el $r m s=0,62^{\prime \prime}$. No obstante, el Seeing se presenta bajo y estable hacia el final de las noches del 20 y 22 de febrero de 2105 con valores alrededor de $2^{\prime \prime}$. La elevada nubosidad del lugar relacionada con su ubicación en la ladera de la montaña, impidió la adquisición de un número suficiente de datos de Seeing. Adicionalmente, la contaminación lumínica en el Museo Paleontológico es enorme toda vez que se encuentra en la periferia del municipio y rodeado por postes de alumbrado público a menos de treinta metros de distancia, viviendas y centros recreativos. No se recomienda este lugar para la ubicación de instrumentación astronómica en el óptico sin antes iniciar un programa de protección de los cielos oscuros en las inmediaciones del lugar.

\section{Análisis comparativo}

Con el objetivo de cuantificar las diferencias entre los valores de Seeing obtenidos con el DIMM, en los seis lugares de interés, es útil considerar la Función de Distribución Acumulada (FDA en adelante) de dichas medidas. En la Figura 11 se muestran las FDA asociadas a cada lugar visitado durante la campaña. En todos los casos, las FDA

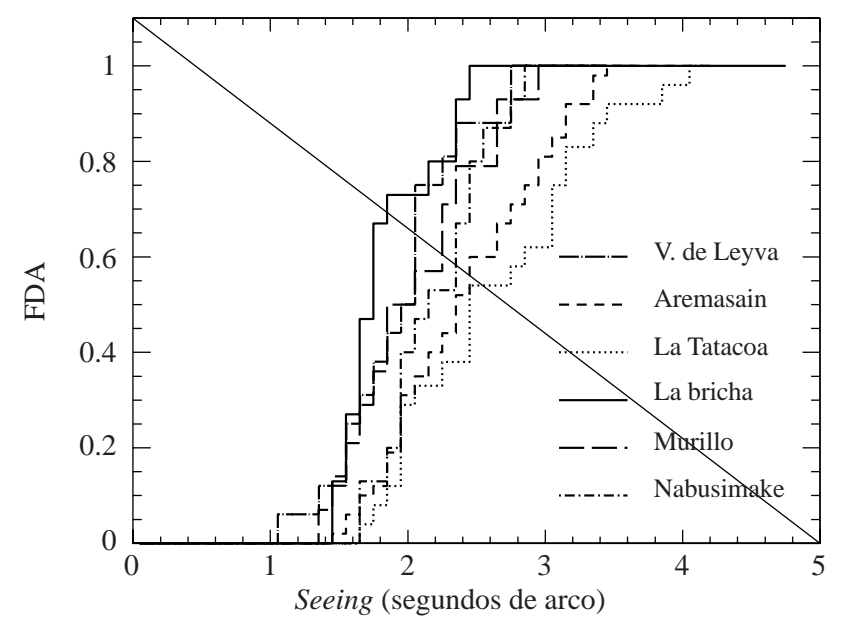

Figura 11. Función de distribución acumulada (FDA) de las medidas de Seeing en seis lugares en Colombia.

cubren el intervalo entre $1^{\prime \prime}$ y 4 " con leves diferencias. La Bricha se destaca como el lugar con los valores de Seeing más bajos. La Tatacoa y Aremasain por el contrario presentan los valores más altos mientras que en Nabusimake, Villa de Leyva y Murillo se observan valores intermedios. El grafico sugiere una dependencia con la altura del lugar, con Seeing mayores en La Tatacoa y en Aremasain mientras valores inferiores a 2" se observan en los cuatro lugares restantes.

Investigamos la significancia de las diferencias relativas entre los seis sitios aplicando una prueba de Kolmogorov-Smirnov (KS) a muestras de valores de Seeing por pares de sitios con el fin de evaluar la probabilidad que ambas provengan de la misma distribución estadística. Si las variaciones son significativas, la probabilidad KS será muy baja y lo contrario, si las muestras son parecidas, la probabilidad KS será alta. La probabilidad $K S$ depende del valor de la máxima diferencia $D$ entre dos FDA. La función que se usa para el cálculo de la probabilidad es (Press, et al. 2007):

$$
Q_{K S}(x)=2 \sum_{j=1}^{\infty}(-1)^{j-1} e^{-2 j^{2} x^{2}}
$$

en donde $Q_{K S}(0)=1$ y $Q_{K S}(\infty)=0$. Para dos muestras con un número de datos $N_{1}$ y $N_{2}$, la probabilidad $K S$ está dada por la siguiente relación:

$$
\begin{array}{r}
P_{K S} \equiv P(D>)= \\
Q_{K S}([\sqrt{n}+0,12+0,11 / \sqrt{n}] D)
\end{array}
$$

$P(D>)$ es la probabilidad que la diferencia entre dos FDA sea mayor a $D$ y $n=N_{1} N_{2} /\left(N_{1}+N_{2}\right)$. Consideremos dos FDA asociadas a lugares con diferencias notorias en el Seeing como La Bricha y La Tatacoa. Para este caso, la máxima diferencia entre las FDA medida sobre la ordenada en la Figura 11, es igual a $D=0,37$ correspondiente a una probabilidad $P_{K S}=0,01$, confirmando variaciones significativas en el Seeing en estos dos lugares. Una 
probabilidad similar $P_{K S}=0,03$ se obtiene al comparar La Bricha con Aremasain sugiriendo que el Seeing en La Bricha es menor debido a que se encuentra a mayor altura.

La Tabla 3 contiene la probabilidad obtenida al hacer la comparación entre pares de sitios. Los lugares con valores de Seeing más parecidos son La Tatacoa y Aremasain con $P_{K S}=$ 0,97, Murillo y Nabusimake con $P_{K S}=0,96$, Nabusimake y Villa de Leyva con $P_{K S}=0,95$, Murillo y Villa de Leyva con $P_{K S}=0,93$ y Murillo y La Tatacoa con $P_{K S}=0,92$. En este último caso, es importante anotar que las medidas hechas con el DIMM en Murillo se realizaron bajo condiciones de extrema humedad en las cuales la condensación de vapor de agua sobre la superficie del espejo del telescopio puede aumentar considerablemente el tamaño de las fuentes puntuales observadas. Notorias diferencias en las medidas realizadas con el DIMM se observan al comparar las FDA correspondientes a La Bricha y Murillo con $P_{K S}=0,11$ y en el resto de lugares se obtienen probabilidades intermedias con valores entre 0,26 y 0,62. Las diferencias en lugares de altura similar no son significativas puesto que la probabilidad en general es mayor a 0,9 exceptuando el caso La Bricha y Nabusimake para el cual se obtiene $P_{K S}=0,37$. Las medidas realizadas en Nabusimake no cubren toda la noche debido al mal tiempo, por lo que la comparación con este lugar está contaminada por incompletos de la muestra.

El valor cuadrático medio de las medidas de Seeing obtenidas en cada lugar es una medida de la variabilidad registrada en el sitio. En La Bricha se obtuvo el menor valor $r m s=0,63^{\prime \prime}$ y si adicionalmente se considera la uniformidad en las variables temperatura y humedad registradas durante la visita a sitio podemos concluir que de los sitios analizados en este estudio La Bricha es el lugar con mayor estabilidad atmosférica. No obstante, por lo menos tres aspectos deben mencionarse. En primer lugar, las medidas se efectuaron durante pocas noches lo que conduce a extrapolaciones erróneas del comportamiento histórico de la calidad de la noche en cada sitio. Además, las condiciones de observación estuvieron marcadas por una humedad elevada lo que impidió adquirir suficiente información sobre la extinción atmosférica y finalmente no todos los lugares visitados coincidieron exactamente con los lugares predichos en el estudio previo. De manera que la selección de La Bricha

Tabla 3. Probabilidad KS que las dos series de datos de Seeing realizadas con el DIMM en cada uno de los pares de lugares indicados, provengan de la misma distribución estadística.

\begin{tabular}{cccc}
\hline & $P_{K S}$ & & $P_{K S}$ \\
\hline MAC-ARE & 0,03 & MUR-VDL & 0,93 \\
MAC-TAT & 0,01 & NAB-ARE & 0,36 \\
MAC-NAB & 0,37 & NAB-TAT & 0,46 \\
MAC-MUR & 0,11 & NAB-VDL & 0,95 \\
MAC-VDL & 0,26 & VDL-ARE & 0,49 \\
MUR-ARE & 0,81 & VDL-TAT & 0,63 \\
MUR-TAT & 0,92 & TAT-ARE & 0,97 \\
MUR-NAB & 0,96 & & \\
\hline
\end{tabular}

como el mejor lugar para la ubicación de instrumentación astronómica debe considerarse con cautela toda vez que es fundamental realizar un monitoreo continuo y a largo plazo del lugar antes de comenzar cualquier proyecto que involucre la ubicación de instrumentación astronómica en este sitio.

\section{Conclusiones}

En este trabajo, presentamos los resultados de un estudio sobre calidad del cielo para observaciones astronómicas en los siguientes seis sitios del territorio colombiano: La Tatacoa (Huila), Macaravita (Santander), Murillo (Tolima), Aremasain (La Guajira), Villa de Leyva (Boyacá) y Nabusimake (Cesár). Se realizaron expediciones esporádicas y de corta duración a dichos lugares entre los años 2013 a 2015, durante las cuales se recopiló información in-situ sobre el comportamiento de la temperatura, la humedad, el Seeing y el brillo del cielo. La humedad registrada en todos los lugares con excepción de Aremasain fue superior al 85\% después de media noche, hecho que afectó notablemente la obtención de medidas fotométricas confiables. Por esta razón el criterio de selección del lugar con condiciones de cielo medianamente óptimas se realizó con base en las medidas in-situ del Seeing atmosférico.

Utilizando la técnica DIMM, se realizó un monitoreo continuo durante cada una de las noches de nuestra visita a cada lugar, siempre que las condiciones de cubrimiento de nubes lo permitieron. Los resultados obtenidos para los lugares de Villa de Leyva, La Bricha, Aremasain y La Tatacoa, se validaron usando un conjunto de 20 imágenes satelitales diarias, en tres bandas en el infrarrojo y simultáneas con la estancia en el lugar, obtenidas de la base de datos del satélite geoestacionario GOES 13. Si bien, el método de validación es fuertemente dependiente de las condiciones de cielo despejado en el lugar, se registró una diferencia porcentual del 5\% entre las medidas in-situ con la predicción satelital, en la vereda La Bricha, un corregimiento del municipio de Macaravita en Santander. En La Tatacoa, Aremasain y Villa de Leyva las diferencias porcentuales fueron respectivamente $26 \%, 36 \%$ y $51 \%$.

La variabilidad de las medidas realizadas con el DIMM en estos cuatro sitios también fue considerada, con base en el valor cuadrático medio obtenido para la totalidad de las noches en el lugar. Se incluyeron todas las noches con el fin de obtener un valor para cada sitio. En Villa de Leyva y en La Bricha, dos lugares con altitud similar arriba de los 2000 metros sobre el nivel del mar, se obtienen $r m s=0,62$ " y $r m s=0,63^{\prime \prime}$ respectivamente. Variabilidad mayor se observa en lugares de baja altura como La Tatacoa con $r m s=0,80^{\prime \prime}$ y Aremasain, $r m s=0,83^{\prime \prime}$ confirmando la dependencia del Seeing con la altura del lugar.

La baja humedad de Aremasain permitió determinar parámetros fotométricos en el lugar. Se obtuvieron los valores del punto cero y del coeficiente de extinción atmosférica en los 
filtros $B, V$ e $I$ a partir del análisis de imágenes de estrellas estándar observadas a masas de aire distintas. El valor promedio del coeficiente de extinción para 4 noches de observación es $(0,66 \pm 0,11)$ magnitudes por masa de aire en el filtro $B$, $(0,30 \pm 0,13)$ magnitudes por masa de aire en $V y(0,33 \pm 0,15)$ magnitudes por masa de aire en el filtro $I$. La elevada humedad en los otros sitios impidió obtener un número suficiente de imágenes en los tres filtros con señal ruido aceptable.

El brillo del cielo se evaluó en cuatro de los seis lugares visitados durante la campaña, a partir de mediciones diarias que cubren 360 grados en acimut y tres valores de altura: sobre el horizonte, a 45 grados y en el cenit. El brillo promedio en el cenit y expresado en magnitudes por segundo de arco al cuadrado igual a 21,83 en La Bricha, 21, 41 en Aremasain, 21,32 en Murillo y 21,20 en La Tatacoa.

Este trabajo se constituye en el primer estudio realizado en Colombia con el objetivo de identificar sitios potenciales para la ubicación de instrumentación astronómica. A pesar de estar dentro la ZCIT, se logran identificar en el país, sitios con calidad aceptable para la el pleno desarrollo de proyectos que fortalecerán actividades de investigación y de extensión en las Universidades. Si bien, el análisis presentado aquí está lejos de ser completo, con seguridad fortalece la discusión de las distintas iniciativas surgidas de la naciente comunidad astronómica colombiana para la conformación de un observatorio profesional nacional.

\section{Agradecimientos}

El desarrollo de este trabajo ha sido posible gracias al apoyo de COLCIENCIAS y de la Universidad Nacional de Colombia a través del proyecto No. 110152129320. Los autores agradecen los comentarios y sugerencias realizados por los jurados de la revista, los cuales permitieron mejorar considerablemente la versión final del manuscrito.

\section{Conflicto de intereses}

Los autores declaran que no tienen conflicto de intereses.

\section{Bibliografía}

Allen, C. W. (1973) Astrophysical Quantities. 3rd ed., The Athlone Press, London.

Bessel, M.S. (1990) UBVRI passbands. Publications of the Astronomical Society of the Pacific, 102: 1181-1199.

Boumis, P., Steiakaki, A., Mavromatakis, F., Paterakis, G. \& Papamastorakis, I. (2001), Seeing measurements at Skinakas Observatory using the DIMM method. Memorias de 5th Hellenic Astronomical Conference, 1: 143-146

Brieva, E. (1985), Búsqueda de sitio para una estación astrofísica en Colombia: Resultados preliminares. Revista Mexicana de Astronomía y Astrofísica, 10: 397-403.

Cavazzani, S., Ortolani, S., Zitelli, V. and Maruccia, Y. (2011), Fraction of clear skies above astronomical sites: a new analysis from the GOES12 satellite, Monthly Notices of the Royal Academy Society, 411: 1271-1283.

Cavazzani, S., Ortolani, S. and Zitelli, V. (2012), Site testing at astronomical sites: evaluation of seeing using satellite- based data. Monthly Notices of the Royal Academy Society, 419: 3081-3091.

Della Valle, A., Maruccia,Y., Ortolani, S. and Zitelli, V. (2010), Analysis of the fraction of clear sky at the La Palma and Mt Graham sites, Monthly Notices of the Royal Academy Society, 401: 1904-1916.

Erasmus, D.A. and Sarazin, M. (2002), Utilizing satellite data for evaluation and forecasting applications at astronomical sites. ASP Conf. Ser., Ed. J. Vernin, Z. Benkhaldoun, and C. Muñoz-Tuñon, 266: 310 .

González, D. (2014), Estudio de la calidad del cielo para observaciones astronómicas en Colombia. Tesis de grado Maestría en Ciencias: Astronomía, Observatorio Astronómico, Facultad de Ciencias, Universidad Nacional de Colombia, Bogotá.

Hidayat, T., Mahasena, P., Dermawan, B., Hadi, P. and Premadi, P. W. (2012), Clear sky above Indonesia: an analysis for astronomical site selection, Monthly Notices of the Royal Academy Society, 427: 1903-1917.

Lawson, J. K. \& Carrano, C. J. (2006), Using historic models of $\mathrm{Cn} 2$ to predict $\mathrm{r} 0$ and regimes affected by atmospheric turbulence for horizontal, slant and topological paths. Memorias del SPIE Optics and photonics, UCRL-CONF222540, San Diego, CA.

Parenti, R. \& Sasiela, R. (1994), Laser guide star systems for astronomical applications. J. Opt. Soc. Am., 11 (1): 288-30.

Pinzón, G., González, D. \& Hernández, J. (2015), Identification of potential sites for astronomical observations in northern South America. Publications of the Astronomical Society of the Pacific, 127 (952): 523-539.

Poveda, G. \& Álvarez, D. (2011), Hydroclimatic variability over the Andes of Colombia associated with ENSO: A review of climatic processes and their impact on one of the Earth's most important biodiversity hotspots. Climate Dynamics, 36: 2233.

Press, W. H., Teulolsky, S. A., Vetterling, W. T. \& Flannery, B. P. (2007), Numerical Recipes, the art of scientific computation, Cambridge Unviersity Press, 3a. edición

Ramírez, A. (2014), Medidas de extinción atmosférica en los filtros $\mathrm{B}$, V, e I en La Guajira, Huila, Santander y Cesár. Tesis de grado Carrera de Física, Departamento de Física, Facultad de Ciencias, Universidad Nacional de Colombia, Bogotá.

Roddier, F. (1981), The effect of atmospheric turbulence in optical astronomy. Progress in Optics, 19: 281.

Rufener, F. (1986), The evolution of atmospheric extinction at $\mathrm{La}$ Silla. Astronomy and Astrophysics, 165: 275-286.

Sarazín, M. \& Roddier, F. (1990), The ESO differential image motion monitor. Astronomy and Astrophysics, 227: 294-300.

Sigernes, F., Peters, N., Lorentzen, D. (2009), The absolute sensitivity of digital colour cameras. Optics Express, 17, 22: 20211-20220.

Stetson, P. (1988) Some Factors Affecting the Accuracy of Stellar Photometry with CCDs. DAO preprint.

Stock, J. (1964), Procedures for location of astronomical observatory sites. IAU Bulletin, 19: 35.

Tatarski, V. (1971), The effect of turbulent atmosphere on wave propagation in a turbulent medium. I:P:S:T:, Jerusalén. 